\title{
Estudo prospectivo de gestantes e seus bebês com risco de transmissão de toxoplasmose congênita em município do Rio Grande do Sul
}

\author{
Prospective study of pregnants and babies with risk of congenital toxoplasmosis \\ in municipal district of Rio Grande do Sul
}

\author{
Sílvia Maria Spalding ${ }^{1,2}$, Maria Regina R. Amendoeira ${ }^{3}$, Luis Carlos Ribeiro ${ }^{4}$, \\ Cláudio Silveira ${ }^{5}$, Aparecida P. Garcia ${ }^{6}$ e Léa Camillo-Coura ${ }^{7}$
}

\begin{abstract}
Resumo A população estudada foi composta por 2.126 gestantes atendidas em unidades do Sistema Único de Saúde da região noroeste do Estado do Rio Grande do Sul. Após o screening sorológico inicial ocorreu o acompanhamento das gestantes, durante o pré-natal, e de seus bebês. Foram realizadas dosagens de IgG, $\lg M$, IgA, Avidez de IgG, inoculação em camundongos, PCR e coleta de placenta e de cordões umbilicais para realizar a técnica de imuno-histoquímica além de avaliações clínicas. Das gestantes avaliadas, 74,5\% eram IgG reagentes e 3,6\% IgM reagentes. Nas avaliações oftalmológicas, foi observada lesão em dez gestantes e uma criança apresentou lesões oftalmológicas e calcificações cerebrais. A presença de lgM específico antiT.gondii, durante toda a gestação não caracterizou a fase aguda recente da infecção, fazendo-se necessária a realização de testes complementares. Ressalta-se a importância do acompanhamento de neonatos de mães com sorologia compatível com a infecção mesmo sem sinais e sintomas sugestivos de toxoplasmose congênita. Palavras-chaves: Toxoplasmose congênita. Transmissão. Acompanhamento. Sorologia.
\end{abstract}

Abstract This study followed up 2,126 pregnant women cared for at SUS day-care clinics (Public Health Insurance System) of the northwest of the State of Rio Grande do Sul, Brazil. After serological screening we performed a follow up of all pregnant women and their babies. Serologic tests included: $\lg G, \lg M, \lg A$ and $\lg G$ avidity levels, mice inoculation and polymerase chain reaction (PCR) also placentas and umbilical materials were tested using immunoperoxidase as well as clinical evaluation. Of all the pregnant women screened, $74.5 \%$ were reactive to toxoplasmosis, and 3.6\% presented IgM seropositivity. At ophthalmic evaluation ten women had ocular lesions and one infant presented eye lesions and brain calcification. The presence of anti-T.gondii specific lgM throughout the entire pregnancy did not characterize acute phase infection, for this, complementary tests were necessary. The importance is underscored for attendance of the newborn of mothers presenting serology compatible with this infection even in the absence of signs and symptoms of congenital toxoplasmosis.

Key-words: Congenital toxoplasmosis. Transmission. Attendance. Serology.

A toxoplasmose é uma protozoose de ampla distribuição geográfica e a transmissão congênita pode ocorrer quando a mulher adquire a primoinfecção durante a gestação. Destes casos, 90\% são assintomáticos ou oligossintomáticos ${ }^{37}$.

O parasita atinge o concepto por via transplacentária causando danos de diferentes graus de gravidade, dependendo da virulência da cepa do parasita, da capacidade da resposta imune da mãe e do período gestacional em que a mulher se encontra, podendo resultar, inclusive, em morte fetal ou em graves manifestações clínicas ${ }^{13}$.

A infecção fetal poderia ser atenuada ou prevenida quando há tratamento materno após um diagnóstico precoce $^{37}$. Em diferentes países, a freqüência de aquisição de toxoplasmose durante a gravidez varia de

\footnotetext{
1. Laboratório Central do Estado da Secretaria da Saúde do Estado do Rio Grande do Sul da Fundação Estadual de Produção e Pesquisa em Saúde, Porto Alegre, RS. 2. Faculdade de Farmácia da Universidade Federal do Rio Grande do Sul, Porto Alegre, RS. 3. Departamento de Protozoologia do Instituto Oswaldo Cruz da Fundação Oswaldo Cruz, Rio de Janeiro, RJ. 4. Hospital da Criança Santo Antônio, Porto Alegre, RS. 5. Escola Paulista de Medicina. 6. In memoriam, Departamento de Anatomia Patológica do Instituto Fernandes Figueira da Fundação Oswaldo Cruz, Rio de Janeiro, RJ. 7. Instituto de Pesquisa Clínica Evandro Chagas e Departamento de Ciências Biológicas da Escola Nacional de Saúde Pública da Fundação Oswaldo Cruz, Rio de Janeiro, RJ. Endereço para correspondência: Dra. Sílvia Maria Spalding. Dept ${ }^{\circ}$ de Análises/UFRGS. Av Ipiranga 2753, 90610-000 Porto Alegre, RS, Brasil. Tel: $55513339-3653$

Recebido em 01/4/02

Aceito em 6/6/2003
} 
1 a 14 casos por 1.000 gestações; no entanto, a infecção congênita ocorre em 0,2 a 2 recém-nascidos por 1.000 nascimentos ${ }^{36}$.

Em alguns países, como França e Áustria, a pesquisa sorológica é, por lei, obrigatória. Tal procedimento reduziu a incidência da toxoplasmose fetal de $40 \%$ para $7 \% 8$.

A toxoplasmose pode passar desapercebida no momento do nascimento, porém poderá se manifestar meses ou até anos depois. Nesses casos, as manifestações mais freqüentes são retinocoroidite e alterações neurológicas. Nos casos mais graves de infecção congênita, o recém-nascido pode apresentar modificação do volume craniano, calcificações intracerebrais e/ou convulsões. No soro do recémnascido, a presença de títulos elevados de anticorpos IgG, que aumentam ou permanecem positivos em período de até 18 meses, é indicativo de toxoplasmose congênita, já que os que decrescem e tendem a se tornar negativos representam os anticorpos maternos de transferência passiva ${ }^{8}$.

A região noroeste do Estado do Rio Grande do Sul, colonizada por descendentes de imigrantes europeus, principalmente italianos, alemães e poloneses, apresenta estrutura econômica associada à agropecuária, com a cadeia produtiva ligada ao processamento de suínos. A região apresenta a maior ocorrência mundial de toxoplasmose ocular, atribuída à forma de retinocoroidite toxoplásmica adquirida, com a prevalência de $17,7 \%$ na população rural de Erechim ${ }^{31} 3233$.

O desconhecimento da soroprevalência de toxoplasmose em gestantes dessa região e a elevada prevalência de problemas oculares associados à infecção por T. gondii, forneceram subsídios para a realização deste trabalho, com vistas a conhecer a ocorrência primária de toxoplasmose em bebês nascidos de mulheres suspeitas de fase aguda de infecção durante a gestação e verificar a necessidade de implantar medidas de prevenção.

\section{MATERIAL E MÉTODOS}

Este trabalho foi realizado na 11a Coordenadoria Regional de Saúde (CRS), constituída por 31 municípios e situada na região do Alto Uruguai, noroeste do Estado do Rio Grande do Sul, no Planalto Meridional do sul do Brasil $\left(27^{\circ}\right.$ de latitude sul e $52^{\circ}$ de longitude oeste). A população estudada foi composta por gestantes atendidas, durante o pré-natal, em unidades do Sistema Único de Saúde.

Todas as gestantes que participaram do projeto foram informadas dos objetivos da pesquisa e assinaram um termo de consentimento de forma livre e esclarecida. Todas as pacientes e seus filhos tiveram acompanhamento clínico e medicação gratuita, quando necessária.

Realizou-se um estudo seccional em 2.126 gestantes de 12 a 48 anos, no período de 15 de julho de 1997 a 31 de dezembro de 1998. Em todas as gestantes foi efetuada, no mínimo, uma coleta de sangue para a realização de dosagens sorológicas de imunoglobulinas de classe IgG através dos testes de imunofluorescência indireta (IFI - Coutinho et al modificada $^{12}$ - o antígeno utilizado foi SALCK) e IgM pela enzyme linked immunosorbent assay (ELISA CAPTIA $^{\text {TM }}$ Toxo-M da Trinity Biotech).

Após o screening sorológico inicial, foram constituídos dois grupos, que tiveram acompanhamento através de estudo prospectivo, durante o pré-natal e após o parto até o primeiro ano de vida do bebê. Para a classificação das pacientes e inserção nos grupos, foram utilizados como critérios: os resultados dos testes sorológicos (as gestantes IgG e IgM não reagentes foram classificadas no grupo I, considerado como grupo controle, e as gestantes IgG e IgM reagentes foram classificadas no grupo II) e a ordem cronológica de entrada no atendimento do pré-natal.

Grupo I. Formado por 31 mulheres e os seus 31 respectivos neonatos. A primeira coleta foi realizada por ocasião da entrada da mãe no atendimento do programa pré-natal e 20 dias após realizou-se nova coleta para os exames confirmatórios, detecção de lgG e lgM (ELISA e IFI) e de IgA por enzimoimunoensaio em micropartículas (MEIA - IMx ${ }^{\circledR}$ Toxo lgA). Nesta mesma data, foi obtido sangue com EDTA para tentar evidenciar o parasita por meio de inoculação em camundongos e PCR. Todas as pacientes foram acompanhadas sorologicamente (dosagens de lgG, $\lg M$ e $\lg \mathrm{A}$ ) com coletas trimestrais.

No momento do parto, de cinco mulheres coletaramse as placentas, das quais foram retiradas 5 amostras com $1 \mathrm{~cm}^{3}$ para realizar a técnica de imuno-histoquímica (método de avidina-biotina-peroxidase com anticorpo policlonal anti-T.gondii, DAKO), inoculação em camundongos (via intraperitoneal linhagem CF1) e a PCR (primer do gene B1 e do TGR-ABGTg7C1 e N1).

No primeiro contato com as crianças após o parto, foi coletado sangue com EDTA para a inoculação em animais e PCR e sangue sem EDTA para a realização de pesquisa de $\lg \mathrm{G}$, $\lg \mathrm{M}$, $\lg \mathrm{A}$, como descrito acima.

Todas as mães e seus filhos (14 do sexo feminino e 17 do masculino) foram acompanhados clínica e sorologicamente (detecção de $\lg$ e $\lg M$ repetidos trimestralmente) até o final do primeiro ano de vida da criança.

Grupo II. Formado por 50 gestantes e seus 51 recém-nascidos (um parto gemelar). No momento do parto, de 18 mulheres coletaram-se as placentas, das quais foram retiradas 5 amostras com $1 \mathrm{~cm}^{3}$ para realizar a técnica de imuno-histoquímica, inoculação em camundongos e PCR. Efetuaram-se também as mesmas metodologias em quatro cordões umbilicais.

Neste grupo II, além dos métodos de diagnóstico efetuados no grupo I, foi realizada a reação de avidez de IgG (MEIA). 
Todas as mães e seus filhos ( 25 do sexo feminino e 26 do masculino) foram acompanhados clínica e sorologicamente até, no mínimo, o final do primeiro ano de vida da criança. Três crianças, por permanecerem com sorologia positiva após 12 meses de idade, foram acompanhadas por maior período de tempo, sendo que uma delas até 2 anos e 7 meses, por apresentar sintomatologia característica de toxoplasmose congênita.

As pacientes com sorologia não reagente (lgG, IgM e IgA) não apresentaram contato prévio com o T. gondii e portanto sem o risco de transmissão fetal da infecção, mas com o risco de aquisição de infecção primária aplicando-se a prevenção primária.

As pacientes com sorologia reagente ( $\lg G$ e $\lg M)$ demonstraram o risco de infecção recente por T. gondii porém, em virtude da sensibilidade da técnica de ELISA para a detecção de lgM foi necessária a realização de dosagem sorológica de $\lg \mathrm{A}$, que, quando reagente representou uma infecção num período inferior a oito meses. O diagnóstico foi complementado pela determinação dos índices de avidez de lgG que, em níveis baixos (inferior a 30\%) significaram infecção aguda, num período inferior a quatro meses, níveis altos (superior a $60 \%$ ) representaram infecção antiga e os valores intermediários (30 a 60\%) foram confirmados.

Quanto ao tratamento das mães, utilizou-se o esquema proposto por Melamed et al 1997: pirimetamina (Daraprim $\left.{ }^{\circledR}\right)$ - somente após a $14^{\text {a }}$ semana, dose de ataque 200mg dividida em duas doses iguais e, após, $25 \mathrm{mg} /$ dia durante 30 a 60 dias; sulfadiazina (Sulfadiazina ${ }^{\circledR}$ ) - foi utilizada quando o primeiro esquema era contraindicado: $3 \mathrm{~g} / \mathrm{dia}$ em quatro doses diárias por 3 semanas; realizando-se intervalo de 3 semanas e repetido a cada intervalo de 3 semanas até o parto; Espiramicina (Rovamicina ${ }^{\circledR}$ ) - 3g/dia em três doses diárias; Ácido folínico (Leucovorin cálcico ${ }^{\circledR}$, Tecnovorin ${ }^{\circledR}$, Ácido folínico ${ }^{\circledR}$ ) $15 \mathrm{mg}$ de 3 em 3 dias. Como drogas alternativas foram utilizadas sulfametoxasol/trimetoprim (Bactrim ${ }^{\circledR}$ ).
A classificação da infecção congênita foi estabelecida de acordo com os sinais clínicos, com a presença de IgM ou a manutenção de lgG reagente em crianças após 12 meses de idade, com ou sem sintomatologia característica $^{24}$. A avaliação clínica teve como objetivo detectar algum sinal de infecção congênita, basicamente do ponto de vista neurológico e/ou de manifestações generalizadas, tais como: desenvolvimento psicomotor, adenomegalias, hepatoesplenomegalias, alterações do perímetro cefálico e estrabismo.

Do ponto de vista laboratorial, além dos exames específicos (sorológicos), foi realizado o hemograma com contagem de plaquetas.

Com base nos resultados sorológicos e nas avaliações clínicas, foi realizado o exame radiológico e/ ou tomográfico de crânio para busca de calcificações. As avaliações clínicas e os exames laboratoriais foram executados pelos mesmos profissionais.

As mães e seus filhos foram submetidos a avaliações oculares para identificação de eventuais lesões retinocoroidianas. No exame oftalmológico, as lesões observadas foram classificadas em graus de I a $\mathrm{V}$, conforme seu aspecto e probabilidade de caracterização como toxoplasmose ocular ${ }^{16}$ : Grau I típicas: lesões maculares com hiperpigmentação periférica iguais ou superiores a meio diâmetro papilar e ausência de tecidos retiniano e coroidiano na área central das lesões; Grau II - altamente prováveis: lesões não maculares com hiperpigmentação periférica, iguais ou superiores a meio diâmetro papilar; Grau III moderamente prováveis: lesões não maculares com diâmetro inferior a meio diâmetro papilar, com hiperpigmentação periférica ou cobrindo toda a lesão; Grau IV - pouco prováveis: lesões difusas com pouca ou nenhuma pigmentação; Grau V - provavelmente não são toxoplasmose ocular: outras lesões retinianas, como degeneração miópica, entre outras.

\section{RESULTADOS}

Das 2.126 gestantes avaliadas, 74,5\% ( $n=1583)$ eram IgG reagentes, sendo que em 3,6\% $(n=77)$ delas foi detectada a presença de $\operatorname{lgM}$ e $25,5 \%(n=543)$ eram $\lg \mathrm{G}$ e $\lg M$ não reagentes.

Das gestantes do grupo controle (grupo $1 ; n=31$ ): todo acompanhamento foi negativo em termos sorológicos e parasitológicos. Nenhuma gestante deste grupo apresentou lesões oftalmológicas ou qualquer outra manifestação clínica sugestiva de toxoplasmose, não houve casos de soroconversão. Em todas as crianças desse grupo a sorologia, o isolamento parasitário e a PCR foram negativos e não foram constadas alterações clínicas. Em todas a crianças foram efetuadas no mínimo três coletas de sangue durante o primeiro ano de vida.

Das gestantes do Grupo II: os exames parasitológicos (PCR e inoculação em animais) foram negativos, no sangue, nas 18 placentas e nos 4 cordões umbilicais coletados, como também foi negativo o estudo imuno-histoquímico das placentas e cordões umbilicais. O título de IgG (IFI) mais freqüente, na primeira coleta de sangue, foi de $1: 1.024(\mathrm{n}=22 ; 44 \%)$, o maior $1: 32.000$ $(n=2 ; 4 \%)$ e o menor $1: 64(n=2 ; 4 \%)$ (Tabela 1$)$.

Tabela 1 - Resultados sorológicos (IgG- IFI) nas primeiras coletas de sangue correlacionados ao trimestre gestacional das mulheres, do grupo II, atendidas pelo SUS na 11- CRS/RS (1997-1998).

\begin{tabular}{lrcrc}
\hline & \multicolumn{3}{c}{ Trimestre } & Total \\
\cline { 2 - 4 } Títulos (IgG) & 1 & 2 & 3 & \\
\hline $1: 64$ & 0 & 2 & 0 & 2 \\
$1: 256$ & 2 & 3 & 1 & 6 \\
$1: 1.024$ & 11 & 9 & 2 & 22 \\
$1: 4.096$ & 2 & 3 & 2 & 7 \\
$1: 8.192$ & 5 & 4 & 0 & 9 \\
$1: 1.6000$ & 2 & 0 & 0 & 2 \\
$1: 32.000$ & 2 & 0 & 0 & 2 \\
\hline Total & 24 & 21 & 5 & 50
\end{tabular}


Nas gestantes do grupo II, a maioria das amostras $(\mathrm{n}=41,82 \%)$ apresentou títulos de anticorpos IgG estáveis na segunda coleta em comparação à primeira coleta de sangue realizada (Tabela 2 ).

Quarenta gestantes (80\% do Grupo II) mantiveram $\lg \mathrm{M}$ reagente durante toda a gestação e 28 (56\% do total das gestantes deste grupo) apresentaram IgA reagente (Tabela 3 e 4 ).

As distribuições dos resultados das dosagens de $\lg \mathrm{A} e$ de avidez de IgG das 50 gestantes do grupo II (Tabela 4).

Foi efetuado tratamento em $45(90 \%)$ gestantes. Das que não receberam medicação, quatro mulheres

Tabela 2 - Coletas para acompanhamento sorológico (IgG-IFI) nas gestantes da $11^{\text {å }} \mathrm{CRS} / \mathrm{RS}$ atendidas pelo SUS (1997-1999).

\begin{tabular}{lcccccccr}
\hline & \multicolumn{7}{c}{ Títulos de anticorpos $(\operatorname{lgG})$} & Total \\
\cline { 2 - 7 } & $1: 64$ & $1: 256$ & $1: 1.024$ & $1: 4.096$ & $1: 8.192$ & $1: 16.000$ & $1: 32.000$ & 50 \\
\hline $1^{\text {a }}$ coleta & 2 & 7 & 21 & 7 & 9 & 2 & 2 & \\
$2^{\text {a }}$ coleta & & & & & & & & \\
Diminuição* & 0 & 0 & 1 & 2 & 3 & 0 & 2 & 8 \\
Estável & 1 & 7 & 20 & 5 & 6 & 2 & 0 & 41 \\
Aumento* & 1 & 0 & 0 & 0 & 0 & 0 & 0 & 1 \\
\hline
\end{tabular}

* em dois ou mais títulos

Tabela 3 - Coletas para acompanhamento sorológico (IgG-IFI e IgM-ELISA) nas gestantes da 11a CRS/RS atendidas pelo SUS (1997-1999).

\begin{tabular}{|c|c|c|c|c|c|c|c|c|}
\hline Títulos de anticorpo & & & & $\lg G^{*}$ & & & & \\
\hline $\lg M$ ** & $1: 64$ & $1: 256$ & $1: 1.024$ & $1: 4.096$ & $1: 8.192$ & $1: 16.000$ & $1: 32.000$ & Total \\
\hline Reagente & 2 & 4 & 17 & 5 & 9 & 1 & 2 & 40 \\
\hline Não reagente & 0 & 3 & 4 & 2 & 0 & 1 & 0 & 10 \\
\hline
\end{tabular}

* na $1^{\text {a }}$ coleta*ao final da gestação

Tabela 4 - Distribuição das determinações de IgA e de avidez de IgG, conforme o trimestre gestacional nas mulheres da 11 - CRS/RS atendidas pelo SUS (1997-1999).

\begin{tabular}{lccccccc}
\hline & \multicolumn{3}{c}{ IgAA } & & \multicolumn{3}{c}{ videz IgG } \\
\cline { 2 - 3 } \cline { 6 - 7 } Trimestre & reagente & não reagente & & $<30 \%$ & $30-60 \%$ & $>60 \%$ & Total \\
\hline 1 & 4 & 5 & & 0 & 0 & 9 & 9 \\
2 & 15 & 9 & & 0 & 2 & 21 & $24^{*}$ \\
3 & 9 & 8 & & 1 & 0 & 16 & 17 \\
\hline Total & 28 & 22 & & 1 & 2 & 46 & 50 \\
\hline
\end{tabular}

*Uma determinação de avidez de IgG não foi realizada

iniciaram o pré-natal no terceiro trimestre e uma no primeiro; a última somente retornou ao acompanhamento no final do terceiro trimestre.

Nas avaliações oftalmológicas, foi observada lesão em dez gestantes: uma com grau $\mathrm{V}$, de outra etiologia que não toxoplasmose ocular, oito com grau III, lesões moderadamente características, e uma com grau II, altamente provável de retinocoroidite toxoplasmática.

Nas 51 crianças do grupo II não se detectou IgA. Somente em uma criança foi observada IgM específico reagente (IFI), sendo que todas as pesquisas de IgM pelo teste de ELISA foram não reagentes. Deste grupo, 5 crianças $(9,8 \%)$ apresentaram $\operatorname{lgG}$ e $\lg M$ não reagentes na primeira coleta, $27(52,9 \%)$ foram lgG reagentes na primeira coleta e negativaram na segunda e $16(31,4 \%)$ somente negativaram na terceira coleta de sangue. $O$ maior título de IgG (IFI) observado nas crianças foi de $1: 8.192(n=1,2 \%)$ e o mais freqüente observado na primeira coleta foi de 1:64 ( $n=22,43,1 \%)$.
Três (5,9\%) crianças mantiveram sorologia (lgG) reagente após 12 meses de idade: duas com o título de 1:64, assintomáticas, e uma com o de 1:4.096, com sintomatologia compatível com toxoplasmose congênita.

Os testes parasitológicos (inoculação em camundongos e PCR) do sangue de todas as crianças, das amostras do cordão umbilical e da placenta de quatro neonatos apresentaram resultados negativos, assim como o estudo imuno-histoquímico.

Uma criança do grupo II apresentou alterações clínicas: lesões oftalmológicas e calcificações cerebrais diminutas em parênquima encefálico em ambos hemisférios cerebrais, identificadas por tomografia computadorizada (Figura 1).

As lesões oculares foram identificadas no $10^{\circ}$ mês e assim descritas: OD com pequenas lesões periféricas; OE com importante lesão macular grau I, com comprometimento da visão (Figura 2). A mãe da criança iniciou seu pré-natal no terceiro trimestre de 


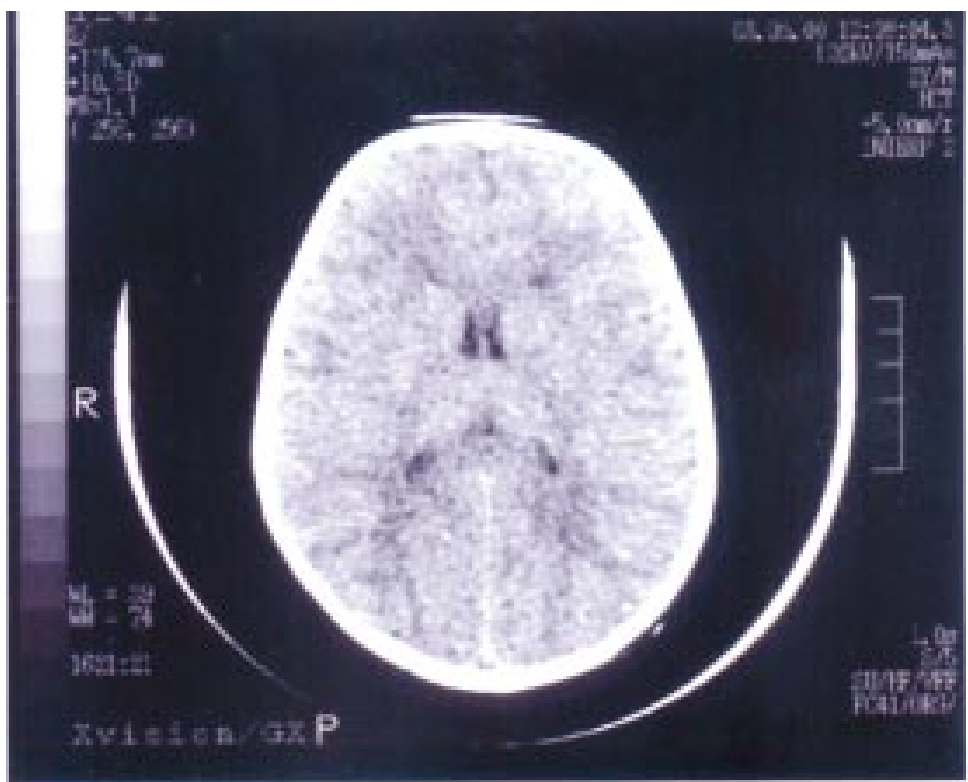

Figura 1 - Calcificações cerebrais diminutas em parênquima encefálico, característica de toxoplasmose congênita com comprometimento cerebral. Registro realizado através de tomografia computadorizada de crânio efetuada sem contraste. Crianla (LK) com 24 meses, pós tratamento.

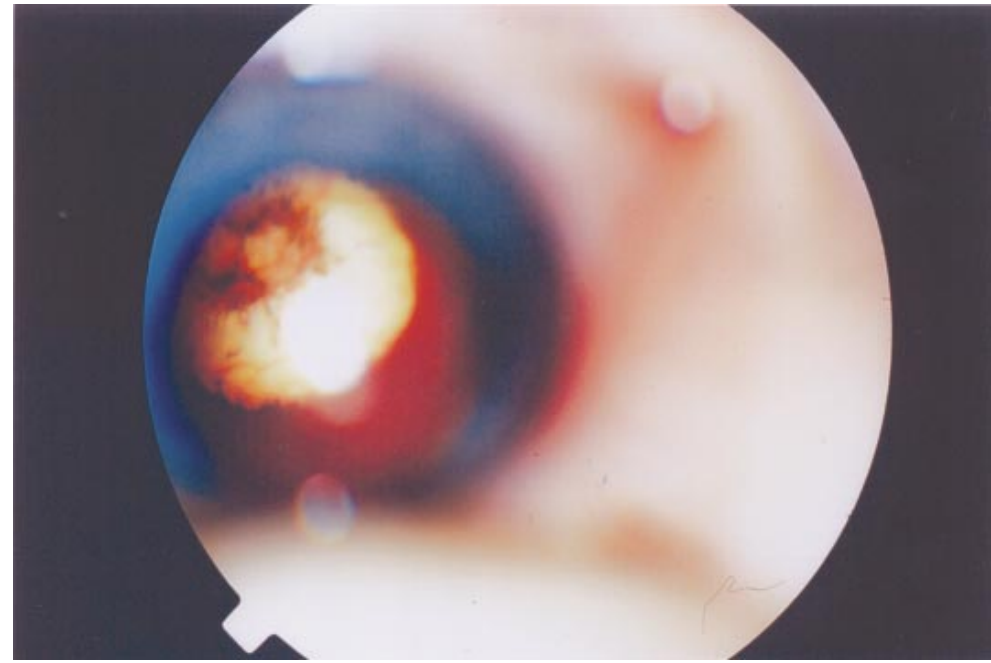

Figura 2 - Lesão macular (OE) grau I, típica de retinocoroidite toxoplásmica congênita aos 12 meses de idade (criança LK), pré-tratamento.

gestação e apresentou IgG (IFI) de 1:4.096, IgM (IFI e ELISA) reagente, IgA reagente e avidez de IgG superior a $60 \%$ e não efetuou o tratamento.

Nesta criança, com 1 ano de idade, foi iniciado o tratamento com duração de 12 meses. Ao segundo exame oftalmológico, aos 2 anos de idade, pós-tratamento, observou-se: OE - retinocoroidite toxoplásmica grau I: cicatrizada, atingindo a área macular (Figura 3); OD retinocoroidite toxoplásmica grau II cicatrizada, atingindo o pólo posterior com mácula preservada (Figura 4).
Duas crianças apresentaram transmissão congênita da infecção por T. gondii, identificadas através da presença de anticorpos da classe IgG após os 12 meses de idade, porém assintomáticas; suas mães receberam terapêutica durante a gestação.

A taxa total de transmissão congênita da infecção por T. gondii nas gestantes do grupo II foi de $6 \%$ (três crianças), sendo que $2 \%$ (uma criança) apresentaram sintomatologia característica da infecção congênita. 


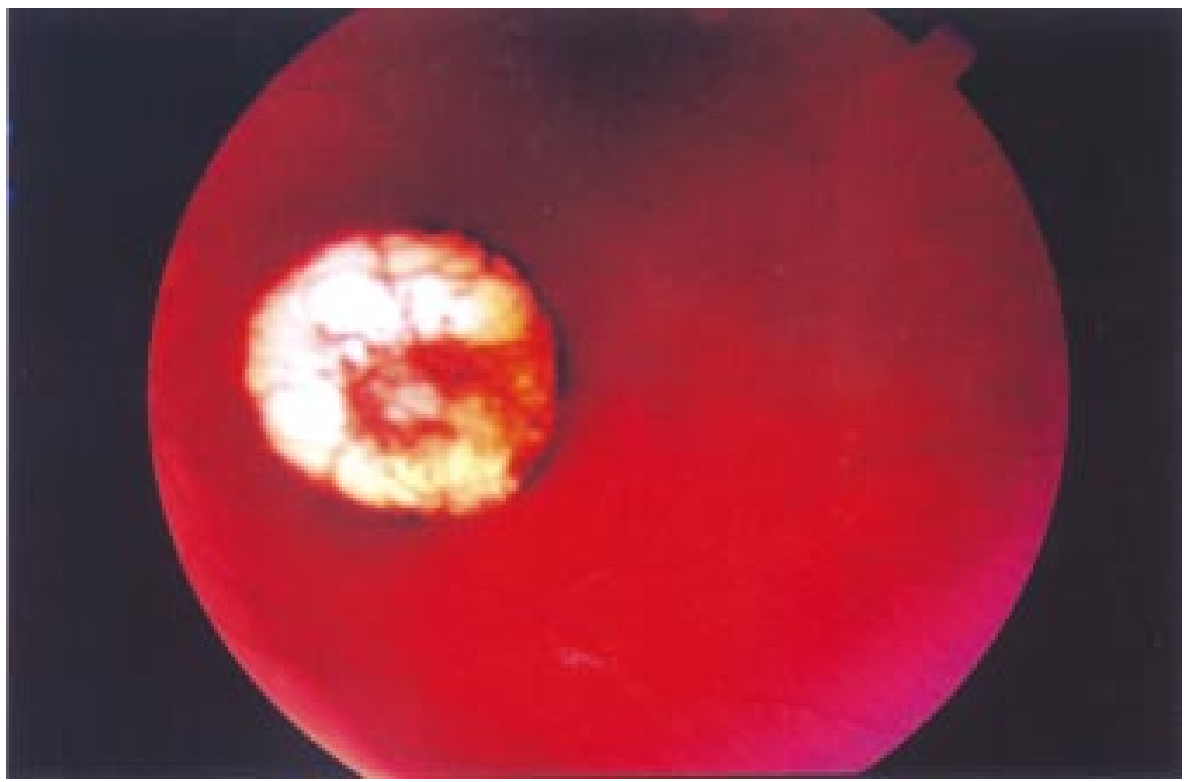

Figura 3 - Lesão macular cicatrizada (OE) grau I, típica de retinocoroidite toxoplásmica congênita aos 24 meses de idade (criança LK), pós-tratamento.

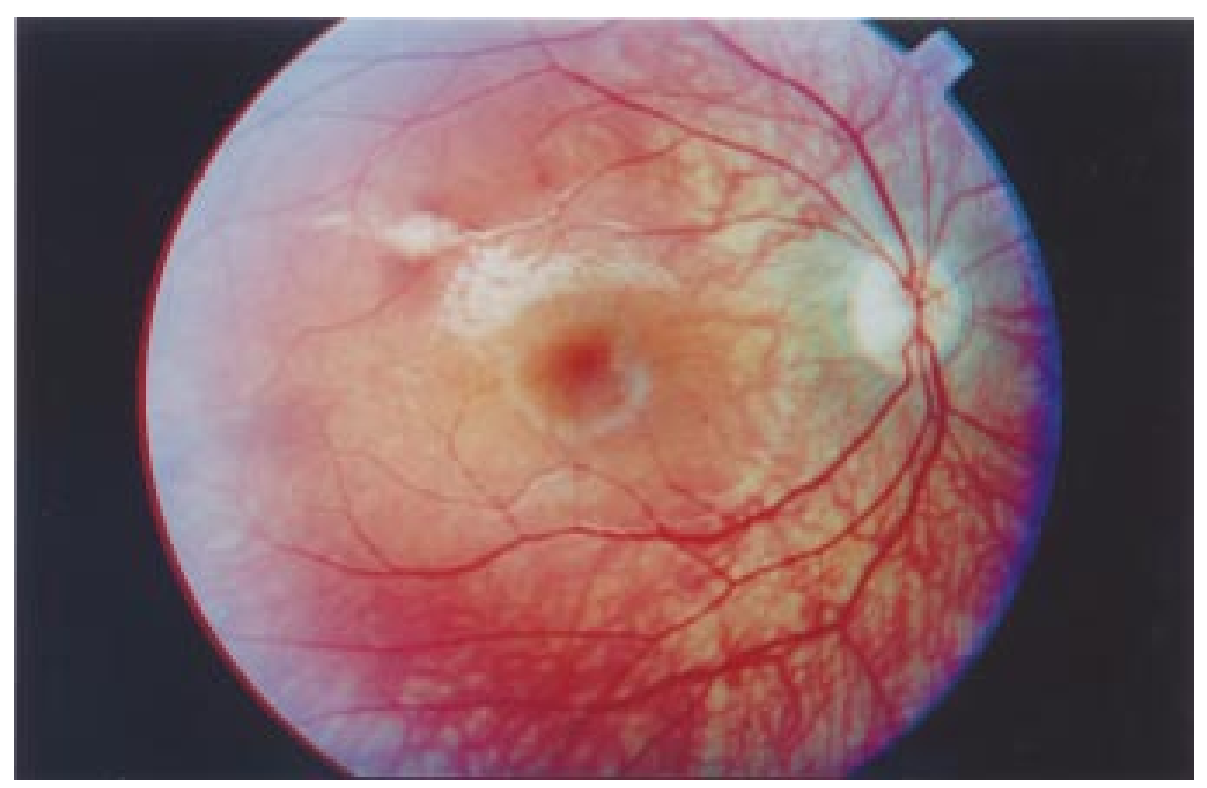

Figura 4 - Lesões periféricas cicatrizadas (OD) de toxoplasmose grau II, aos 24 meses de idade (criança LK), pós-tratamento.

\section{DISCUSSÃO}

A alta prevalência $(74,5 \%)$ da infecção por Toxoplasma gondii, na população estudada, foi superior a da América Latina, 50 a $60 \%{ }^{15}$ e próxima à observada em gestantes do Rio de Janeiro, $78,7 \%{ }^{12}$.

O acompanhamento clínico e sorológico das 31 gestantes do grupo I (controle) justificou-se pelo fato de ser um grupo de risco (soronegativas), o diagnóstico precoce da infecção materna, na soroconversão, poderia evitar a infecção fetal ou atenuá-la através da instituição da terapêutica.

Nesse grupo de gestantes, não houve soroconversão e durante o acompanhamento clínico e sorológico, tanto nas mães quanto nos seus bebês. As medidas de prevenção primárias empregadas no Programa da Saúde da Mulher, no qual a cada encontro 
eram lembradas à gestante as formas de prevenir a infecção pelo T.gondii, podem ter contribuído para isto.

A presença de IgM específico anti- T. gondii, durante toda a gestação, em $80 \%$ das mulheres do grupo II não caracterizou a fase aguda recente da infecção, sendo assim, só pode ser utilizada como screening. Fez-se necessário então efetuar a dosagem de $\lg \mathrm{A}$, de avidez de IgG, testes parasitológicos.

Em nove gestantes do grupo II, foram realizadas pesquisas de $\lg \mathrm{A}$ e avidez de $\lg \mathrm{g}$ no primeiro trimestre. Em todas as amostras observou-se avidez elevada (superior a 60\%), o que indica infecção prévia à concepção.

Das 24 gestantes que realizaram as dosagens de $\lg \mathrm{A}$ e avidez de $\lg \mathrm{G}$ no segundo trimestre, duas apresentaram avidez intermediária (30 a 60\%), uma delas com IgA reagente, o que pode indicar a infecção no primeiro trimestre. Um total de 21 mulheres apresentaram avidez alta (superior a 60\%): oito delas tinham $\lg A$ não reagente, o que indica infecção prévia à concepção, e 14 apresentaram IgA reagente, o que poderia ser indício de infecção no primeiro trimestre ou em um período prévio muito próximo à concepção. Nestes casos o teste de avidez de IgG teve sua importância reduzida para o diagnóstico da infecção congênita, pois o fato de serem as mães no $2^{\circ}$ e $3^{\circ}$ trimestre com avidez intermediária ou elevada não excluía a possibilidade da infecção materna ter ocorrido no $1^{\circ}$ trimestre.

Das 17 mulheres que efetuaram as referidas dosagens no terceiro trimestre, uma apresentou avidez baixa (inferior a $30 \%$ ) com IgA reagente, o que indica a infecção durante a gestação; as 16 restantes apresentaram avidez elevada, 8 delas com lgA reagente, o que aponta a possibilidade de infecção durante o primeiro trimestre, e as outras 8 com $\lg$ A não reagente, sugerindo infecção num período muito próximo e/ou prévio à concepção.

Apesar de ser observada com baixa freqüência, há relatos na literatura de casos de transmissão congênita em crianças nascidas de mulheres que se infectaram com T. gondii antes da concepção, tanto das que apresentavam imunodeficiência como das que apresentavam status imune normal ${ }^{18}$. Nesses casos, deve ser avaliada a possibilidade de reinfecção ou reativação da parasitemia, reinfecção por uma cepa do parasita com virulência aumentada ou com características fenotípicas distintas. Essa possibilidade deve ser valorizada quando se avaliam os resultados sorológicos - IgM reagente, $\lg A$ não reagente e avidez de IgG elevada. Tendo em vista que há relatos de cepas com maior virulência nesta região do Brasil onde foi desenvolvido o estudo, é possível levantar a possibilidade de ocorrer esta manifestação da infecção ${ }^{18}$.

Deve-se alertar para o fato de que a baixa avidez de IgG pode manter-se em alguns pacientes por um tempo maior (meses ou anos), o que diminui o seu valor como marcador diferencial das fases aguda e crônica da infecção por T. gondii. Deve-se também observar com atenção os dados de outros autores ${ }^{311}$, pois eles indicam uma variação da resposta imune, sugerindo uma maturação retardada da resposta imune, que também é observada em casos de linfadenopatias. Não existe correlação entre a clínica e a terapêutica antiparasitária e manutenção das taxas de baixa avidez de IgG; o que ocorreria é a modificação da resposta imune durante a gestação, com uma conseqüente ação na demora da maturação dos anticorpos.

A presença de anticorpo lgM durante a fase crônica da infecção tem sido reportada, o que dificulta a interpretação dos resultados positivos, principalmente na gestação. A importância maior da detecção isolada de IgM é a de determinar se a gestante não está recentemente infectada. Portanto, é necessário associar à determinação do $\lg \mathrm{M}$ a detecção de $\lg \mathrm{A}$, que, por possuir cinética mais rápida, é capaz de identificar com maior segurança a fase aguda da infecção ${ }^{25}$.

O fato do parasita não ter sido evidenciado pelas técnicas de PCR e inoculação em animais susceptíveis provavelmente ocorreu devido à fugaz permanência do $T$. gondii no sangue periférico e, também, porque as pacientes com infecção aguda, sorologicamente comprovada, se encontravam em tratamento. O mesmo deve ter ocorrido, considerandose os resultados negativos, na análise das placentas e cordão umbilical por PCR e imuno-histoquímica.

A taxa de transmissão congênita da infecção toxoplásmica de $6 \%$, encontrada nas gestantes do grupo II, está de acordo com trabalhos realizados em gestantes tratadas (7\%), variando de 1,2 a $28,9 \%$ de acordo com a fase da gestação em que ocorreu a infecção ${ }^{29}$. A taxa, no presente trabalho, poderia ser mais elevada, caso as gestantes não fossem tratadas, pois outros autores têm avaliado em 20 a $70 \%$ o risco em gestantes não tratadas $^{22} 27$. Outros autores consideram que da $10^{\text {a }}$ à $24^{a}$ semana é o período mais crítico em relação à infecção congênita, o que recomenda a instituição do tratamento antiparasitário ${ }^{6}$. Nas 45 gestantes em que foi efetuado o tratamento, 28 (56\% do total das gestantes do Grupo II) iniciaram a terapêutica no segundo trimestre: destas, uma $(3,6 \%)$ criança manteve a presença de IgG por mais de 12 meses, o que indica que não era de transmissão passiva adquirida da mãe, caracterizando portanto a infecção congênita ${ }^{24}$; dezessete (34\%) gestantes iniciaram o tratamento no terceiro trimestre de gestação, sendo que também uma $(5,9 \%)$ criança apresentou a transmissão congênita. Ambas as crianças eram assintomáticas, o que sugere que o tratamento precoce evitou e/ou minimizou lesões compatíveis com toxoplasmose congênita. Das $5(10 \%)$ gestantes que não foram medicadas, uma $(2 \%)$ criança apresentou toxoplasmose congênita com lesões oftalmológicas e calcificações cerebrais. Apesar do pequeno número de pacientes acompanhados, estes dados corroboram os da literatura, que indicam que o diagnóstico e tratamento precoce durante a gestação evitam e minimizaram as lesões no neonato 5610202629 . Isso também pode ser 
observado na criança, filha de mãe não tratada, com toxoplasmose congênita diagnosticada clínica e sorologicamente, que apresentou estabilidade do quadro oftalmológico após tratamento específico.

Mesmo após o tratamento observou-se presença de nova lesão já cicatrizada no polo posterior do OE, mostrando que a medicação não impede a reincidência de novos focos.

O número de casos de toxoplasmose congênita, também, pode ter sido influenciado pelo critério de inserção da gestante no grupo de risco de transmissão congênita do protozoário (presença de IgM em algum momento da gestação). Este critério, em função da cinética do isótipo aí envolvido e da sensibilidade elevada do teste de diagnóstico, provavelmente identificou anticorpos residuais que permaneceram na circulação após a fase aguda da infecção, ou seja, quando a transmissão ao feto não poderia ocorrer. Esse fator é confirmado não apenas através das determinações de lgA (que apresenta cinética mais rápida e desaparece da corrente circulatória entre 6 e 8 meses), mas também pela baixa avidez de IgG observada somente até o $3^{\circ}$ mês após a infecção.

Levando-se em conta a população examinada e analisando-se os dados de presença de anticorpos IgA na amostragem cujo acompanhamento foi efetuado, observa-se que $28(56 \%)$ gestantes apresentaram IgA reagente. Essas pacientes, provavelmente, estavam na fase aguda da infecção por T. gondii durante a gestação. Isto representa $2 \%$ da população avaliada com possibilidade de transmissão congênita da toxoplasmose, por estar na fase aguda da infecção. Essa taxa é considerada alta se comparada à observada nos EUA e França, de 0,2 a $1 \%^{17}{ }^{37}$, na Noruega, de $0,2 \%^{34}$, e na Dinamarca, onde $0,2 \%$ de mulheres soroconverteram na gestação e tiveram $19 \%$ de transmissão ao feto ${ }^{26}$. No presente trabalho, das 51 crianças do grupo II acompanhadas, somente 28 eram nascidas de mães com IgA reagente, provavelmente na fase aguda e com risco de transmissão congênita. Destas crianças, três (10,7\%) apresentaram a transmissão congênita, sendo que uma $(3,6 \%)$ apresentou sintomatologia característica. Inferindose tais dados à população do estudo, encontra-se uma taxa de transmissão de 2,2 em 1.000 nascimentos e de 0,7 em 1.000 nascidos vivos apresentando sintomatologia.

A presença de sintomatologia característica da infecção ao nascimento apresenta-se em $10 \%$ das crianças ${ }^{26}$. Outros pesquisadores encontraram taxas maiores de infecção fetal - 33\% ${ }^{13}, 44 \%$ em 18 mães $^{23}$ - e de sintomatologia característica $-11 \%$ em 180 gestações com a infecção na fase aguda ${ }^{13}$ e $29 \%{ }^{26}$. As taxas de transmissão, no entanto, oscilam conforme o trimestre gestacional, variando de $15 \%$ no primeiro trimestre a $60 \%$ no terceiro trimestre ${ }^{5}$. Por limitações técnicas e do trabalho de campo, a amostragem de seguimento das pacientes aqui realizada foi pequena $(n=50)$; ou seja, foram acompanhadas $64,9 \%$ de todas as gestantes $(n=77)$ que apresentaram anticorpos IgM neste período na região estudada.

Acredita-se que a taxa de $10,7 \%$ de transmissão congênita encontrada nas gestantes com IgA reagente do grupo II, inferior a outras já citadas na literatura, foi resultado do tratamento efetivo realizado durante a gestação uma vez que o tratamento precoce reduz de 40 a $60 \%$ a transmissão congênita da infecção ${ }^{5} 1937$.

As taxas de transmissão congênita e as manifestações clínicas variam de forma acentuada entre os indivíduos com infecção por T. gondii. Dentre os fatores envolvidos, estão variações da resposta imune e idade do hospedeiro, variações étnicas, cepa do parasita, quantidade de inóculo, condições socioeconômicas, hábitos culturais e clima da região envolvida ${ }^{30}$.

Os resultados deste trabalho ressaltam a importância do acompanhamento de neonatos de mães com sorologia compatível com a infecção, ainda que não apresentem sinais e sintomas sugestivos de toxoplasmose congênita. Também mostram a importância das medidas profiláticas primárias na redução da transmissão congênita do $T$. gondii.

\section{REFERÊNCIAS BIBLIOGRÁFICAS}

1. Amendoeira MRR. Diagnóstico de la toxoplasmosis congénita. Revista Cubana de Investigaciones Biomedicas 20:118-21, 2001.

2. Amendoeira MRR, Costa T, Spalding SM. Revista Souza Marques 1:15-35, 1999.

3. Ashbrum D, Joss AWL, Pennington TH, Ho-Yen DO. Do IgA, $\lg E$ and avidity tests have any value in the diagnosis of Toxoplasma infection in pregnancy? Journal of Clinical Pathology 51:312-315, 1998

4. Backt FR, Gentry LO. Toxoplasmosis in pregnancy: an emerging concern for family physicians. American family physician 45:1683-1690,1992

5. Beazley DM, Egerman RS Toxoplasmosis. Seminars in Perinatolology 22:332-338,1998.

6. Berrebi A, Kobuch WE, Bessiéres MH, Rolland M, Sarramon MF, Fournie A. Valeur prédictive des signes non spécifiques d'infection foetale dans la toxoplasmose congénitale. Lancet 344:36-39,1994.

7. Beverley JKA. Toxoplasmosis. British Medical Journal 2:475$478,1973$.

8. Camargo ME. Alguns aspectos atuais do diagnóstico de laboratório da toxoplasmose. Anales de la Real Academia Nacional de Medicina 155:236-239, 1995.

9. Camargo Neto E, Anele E, Rubin R, Brites A, Schulte J, Becker D, Tuuminen T. High Prevalence of Congenital Toxoplasmosis in Brazil Estimated in a 3-year Prospective Neonatal Screening Study. International Journal of Epidemiology 29:941-947, 2000.

10. Chumpitazi BFF, Boussaid A, Pelloux H, Racinet C, Bost M, Goullier-Fleuret A. Diagnosis of congenital toxoplasmosis by immunoblotting and relationship with other methods. Journal of Clinical Microbiology 33:1479-1485,1995. 
11. Cozon GJN, Ferrandiz J, Nebhi H, Wallon M, Peyron F. Estimation of the avidity of immunoglobulin $G$ for routine diagnosis of chronic Toxoplasma gondii infection in pregnant women. European Journal of Clinical Microbiology and Infectious Diseases 17:32-36,1998.

12. Coutinho SG, Souza WJS, Camillo-Coura L, Marzochi MCA, Amendoeira MRR. Levantamento dos resultados das reações de imunofluorescência indireta para toxoplasmose em 6.079 pacientes de ambulatório ou gestantes no Rio de Janeiro realizadas durante os anos de 1971 a 1977. Revista do Instituto de Medicina Tropical de São Paulo 23:48-56,1981.

13. Desmonts G, Couvreur J. Congenital toxoplasmosis: a prospective study of 378 pregnancies. The New England Journal of Medicine 290:1110-1116,1974.

14. Frenkel JK. Pathology and pathogenesis of congenital toxoplasmosis. Bulletin of the New York Academy of Medicine 50: 182-191,1974.

15. Frenkel JK. La inmunidad en la toxoplasmosis. Boletin de la Oficina Sanitaria Panamericana 100:283-295,1986.

16. Glasner PD, Silveira C, Kruszon-Moran D, Martins MC, Burnier M, Silveira S, Camargo ME, Nussenblatt RB, Kaslow RA, Belfort R. An unusually high prevalence of ocular toxoplasmosis in southern Brazil. American Journal of Opthalmology 114:136-144,1992.

17. Guerina NG, Hsu H, Meissner G, Maguire JH, Lynfield R, Stechenberg B, Abroms I, Pasternack MS, Hoff R, Eaton RB, Grady GF, The New England Regional Toxoplasma Working Group. Neonatal serologic screening and early treatment for congenital Toxoplasma gondii infection. The New England Journal of Medicine 330:1858-1863,1994.

18. Hennequin C, Dureau P, N'Guyen N, Thulliez P, Gagelin B, Dufier JL. Congenital toxoplasmosis acquired from an immune woman. Pediatrics Infetions Diseases Journal 16:75-77,1997.

19. Hohlfeld P, Daffos F, Costa JM, Thulliez P, Forester F, Vidaud M. Prenatal diagnosis of congenital toxoplasmosis with a polymerase chain reaction test on amniotic fluid. The New England Journal of Medicine 331: 95-99, 1994.

20. Hohlfeld P, Forestier F, Marion S, Thulliez P, Marcon P, Daffos F. Toxoplasma gondii infection during pregnancy: $T$ lymphocyte subpopulations. Pediatrics Infections Diseases Journal 9:878$881,1990$.

21. Jacobs L. Toxoplasma and toxoplasmosis. Annual Review Microbiology 17:429-450,1963.

22. Koskiniemi M, Lappalainen M, Hedman K. Toxoplasmosis needs evaluation. American Journal of Diseases of Children 143:724728,1989 .

23. Kraubig K. Praventive Behandlung der Konnatalen Toxoplasmose. Toxoplasmose-Praktische Fragen and Ergebnisse. Edited by H Kirchhof. H Kraubig. Stuttgart, Georg Thieme Verlag, p. 104-122,1966.
24. Lebech M, Joyson DHM, Seitz HM, Thulliez P, Gilbert RE, Dutton GN, Ovlisen B, Petersen E. Classification system and case definitions of Toxoplasma gondii infection in immunocompetent pregnant women and their congenitally infected offspring. European Journal of Clinical Microbiology and Infections Diseases 15:799-805,1996.

25. Liesenfeld O, Press C, Montoya JG, Gill R, Isaac-Renton JL, Hedman K, Remington JS. False-positive results in immunoglobulin M (IgM) Toxoplasma antibody tests and importance of confirmatory testing: the Platelia Toxo IgM test. Journal of Clinical Microbiology 35:174-178,1997.

26. Lynfield R, Hsu HW, Guerina NG. Screening methods for congenital Toxoplasma and risk of disease. Lancet 353:18991900,1999

27. McCabe RE, Remington JS. Toxoplasmosis: the time has come. The New England Journal of Medicine 318:313-315,1988.

28. Melamed J, Gus PI, Alvarenga ZE. Tratamento da toxoplasmose ocular na gestação. Revista Brasileira de Oftalmologia 56:241 $248,1997$.

29. Mirlesse V, Jacquemard F, Daffos F. Toxoplasmose au cours de la grossesse: diagnostic et nouvelles possibilités thérapeutiques. La Presse medicale 22:258-262,1993.

30. Remington JS. Toxoplamosis in the adult. Bulletion of the New York Academy of Medicine 50:211-227,1974.

31. Silveira C. Retinocoroidite pressumivelmente toxoplásmica em 6 irmãos não-gêmeos. Arquivos Brasileiros de Oftalmologia 50:88-91,1987.

32. Silveira C, Belfort Jr R, Burnier JR M, Nussemblatt R. Toxoplasmose ocular: identificação de cistos de Toxoplasma gondii na retina de irmãos não gêmeos com diagnóstico de toxoplasmose ocular recidivante. Primeiro caso mundial. Arquivos Brasileiros de Oftalmologia 50:215-218,1987

33. Silveira C, Belfort Jr R, Burnier JR M, Nussemblatt R. Acquired toxoplasmic infection as the cause of toxoplasmic retinichoroiditis in families. American Journal of Ophtalmology 106:362364,1988

34. Stray-Pedersen B. A prospective study of acquired toxoplasmosis among 8043 pregnant women in the Oslo area. American Journal of Obstetrics and Gynecology 136:399403,1980 .

35. Watson WA. Toxoplasmosis in human and veterinary medicine. The Veterinary Record 91: 254-258,1972.

36. Williams KAB, Scott JM, MacFarlane DE, Williams JM, Eliasjones, TF, Willians $\mathrm{H}$. Congenital toxoplasmosis: a prospective survey in the west of Scotland. The Journal of Infection 3:219$229,1981$.

37. Wong SY, Remington JS. Toxoplasmosis in pregnancy. Clinical Infectious Diseases 18:853-862,1994. 